Adolescence during a Pandemic: Examining US Adolescents' Time Use and Family and Peer Relationships during COVID-19

\author{
Laura Wray-Lake ${ }^{1}$, Sara Wilf $^{1}$, Jin Yao Kwan ${ }^{1}$, Benjamin Oosterhoff ${ }^{2}$ \\ ${ }^{1}$ Luskin School of Public Affairs, Department of Social Welfare, University of California, Los \\ Angeles \\ ${ }^{2}$ Department of Psychology, Montana State University
}




\begin{abstract}
Public health recommendations to slow the spread of COVID-19 have resulted in closing schools and businesses and encouraging social distancing, which has reshaped adolescents' ecologies. Adolescents' time use during the pandemic offers insight into their lived experiences in unprecedented times, and adolescents' activities may be shaped in important ways by their relationships and social locations. This study used a person-centered approach to describe distinct profiles of time use and examined the role of demographics, parent conflict, parent support, and friend support in differentiating time use profiles. Using a non-representative national U.S. sample of 555 adolescents, latent profile analysis of hours spent in 14 activities in a typical day identified three typologies of time use. Youth in the Education-Focused group were more likely to be male, had higher parent support, and had lower support from friends. High Media Users were more likely to be female and LGBQ-identifying and had lower parent support and higher friend support. Work-Focused youth, who were distinguished by working for pay, were more likely to be female and spend more time with friends in person. This pattern of findings suggests that the COVID-19 pandemic may be creating distinct trade-offs between family and friend support that map onto how adolescents are spending their time. Results have implications for ways to strengthen relational supports and reconsider the risks and benefits of different types of time use during this stressful period in history.
\end{abstract}

Keywords: pandemic, social media, friendships, parent-adolescent relationships, leisure activities 


\section{Adolescence during a Pandemic: Examining US Adolescents' Time Use and Family and Peer Relationships During COVID-19}

Adolescents' daily lives were abruptly upended during the COVID-19 global pandemic. In mid-March 2020, U.S. adolescents shifted to learning remotely and spending time largely at home and away from peers. To limit the spread of the disease, restrictions on public gatherings although different across states - have persisted for months after. Numerous developmental contexts known to shape adolescent development such as in-school resources and relationships, school and community extracurricular activities, summer jobs, summer camps, recreation spaces, and social time with peers, drastically changed or became non-existent. Shrinking access to developmental contexts and opportunities leave open the question of how U.S. adolescents chose to spend their time during a period of societal upheaval and tragedy. Youth's different social experiences across gender, race/ethnicity, socioeconomic status (SES), and sexual orientation likely shape their experiences of the pandemic (Cohen \& Bosk, 2020) and lead to different patterns of time use. As many youth spent more time at home and adolescents and their families experienced economic, social, and psychological stressors of COVID-19, family conflict has likely increased (Brown et al., 2020), and family relationships - whether conflictual or supportive - may be more salient in shaping adolescents' daily lives. Peer interactions, a cornerstone of adolescent development, have likely shifted to virtual spaces which may alter how adolescents spend their time interacting with technology. Although balancing family and peer relationships has long been understood as a challenging developmental task for adolescents (Collins et al., 1997), family and peer relationships may be producing different sorts of tensions and behavioral patterns for adolescents during COVID-19.

The goal of this study was to examine variability in U.S. adolescents' time use during the 
2020 summer of COVID-19 and explore demographic and relational differences in time use.

Using latent profile analysis (LPA) with a non-representative national sample of 555 U.S. adolescents, we describe patterns of activities that adolescents prioritize in their daily lives during COVID-19. We examine variation in these patterns by gender, race/ethnicity, SES, sexual orientation, parent support and conflict, and friend support. Identifying sources of variability in profiles of adolescent time use may shed light on supports and vulnerabilities that explain the dramatically different ways that adolescents have spent their time during COVID-19.

\section{Adolescents' Time Use}

Adolescents' time use is important from a research and applied perspective because of well-established links between adolescents' daily activities and their health and well-being (Ferrar et al., 2013; Hunt et al., 2015). Adolescents' time spent on various leisure activities provides important insight into positive youth development and thriving, as certain activities build skills or facilitate learning, promote health, enhance social relationships, and contribute to improving community and society (Larson \& Verma, 1999; Silke et al., 2018; Trainor et al., 2010; Vossen \& Valkenburg, 2016). Media and social media use is a growing area of attention in adolescent development research, given that youth are spending larger amounts of time on screens and in virtual spaces during their leisure time (Best et al., 2014; Stiglic \& Viner, 2019). Given substantial variability in how adolescents spend time, person-centered methods are ideal for capturing systematic variation in adolescents' choices of activities (Bartko \& Eccles, 2013; Ferrar et al., 2013). Adolescents' time use profiles vary based on the items used, but demonstrate that youth differ in their emphasis on sports or civic activities, sedentary time, media use, work, school, and health behaviors (e.g., Parker et al., 2019; Sharp et al., 2015; Wolf et al., 2015).

The dramatic societal and life changes due to COVID-19 merit a new look at adolescents' 
time use. Previous research has shown that during the summer, when adolescents are not in school and their days are less structured, physical activity decreases and screen time increases (Brazendale et al., 2017). With limited opportunities for activities and more unstructured time, adolescents' time use during COVID-19 likely reflects a dramatic departure from typical ways that adolescents spent their time pre-COVID-19. Other major national events in the U.S., such as the Black Lives Matter movement and impending national election may compound adolescents' stressors and shape how they choose daily activities. U.S. adolescents' time use can help us understand adolescents' daily life experiences during the pandemic and different ways youth are coping with the changes and stressors brought on by this crisis. Our study focused on adolescents' time spent in various leisure and social pursuits, spanning media use, civic activity, work, self-improvement, and time with friends and family.

Moreover, adolescents have unique developmental experiences based on gender, race/ethnicity, SES, and sexual orientation. People of color and low-income families are experiencing disproportionate impacts of COVID-19, including higher rates of infection and death, greater involvement in essential work that brings heightened health risks, and greater income loss and labor market precarity (van Dorn et al., 2020). During stay-at-home orders, lesbian, gay, bisexual, transgender, queer, and gender non-conforming (LGBTQ) youth are at higher risk for social isolation and victimization at home (Cohen \& Bosk, 2020). Thus, considering demographic differences in youth's choice of activities has important implications for understanding how vulnerable or marginalized groups are experiencing COVID-19.

\section{Media Use}

Adolescents' media use can include many different activities such as watching shows and movies, playing video games, and spending time on various social media sites. In 2019, a 
nationally representative U.S. sample of adolescents reported using an average of 7.5 hours of screen time daily, outside of school work (Rideout \& Robb, 2019). Various studies have documented negative health and mental health consequences of adolescents' high media use, including depressive symptoms, poor sleep, low self-esteem, and heightened substance use (Boer

et al., 2020; Hunt et al., 2018; Ionnatti et al., 2009; Kelly et al., 2018). Likewise, increased social media usage during COVID-19 has been linked to greater rates of depression among adolescents (Ellis et al., 2020). Yet, during the COVID-19 pandemic, social media may be an essential or sole outlet for adolescents to find social connection, seek information about COVID-19 and other current events, and make civic contributions (Orben et al., 2020). In some cases, social media use can also have positive associations with adolescents' mental health, self-esteem, peer relationships, and contributions through civic engagement (Best et al., 2014; Gil de Zúñiga et al., 2012; Jenkins et al., 2018). Certain groups of young people may be particularly drawn to media use. A study across 30 countries found that adolescent boys had much higher rates of screen time than girls (Bucksch et al., 2016), yet girls spent more time than boys on social media (Lin et al., 2016). Black and Latinx adolescents have higher social media usage than peers from other racial backgrounds (Lenhart et al., 2015). LGBTQ youth may turn to social media for important sources of social support (Ybarra et al., 2015). Youth from lower-SES backgrounds may have less consistent access to internet and devices for screen time (Harris et al., 2017), and may engage differently online compared to their higher-SES peers (Micheli, 2016).

\section{Civic Engagement}

According to positive youth development (PYD) theory, youth's contributions to community and society are indicators of thriving (Lerner et al., 2014). During COVID-19, adolescents may be helping neighbors, following news and current events, engaging in political 
discussions, or taking political action on social media related to COVID-19, the Black Lives Matter movement, the election, or other issues. Helping behavior is often positively linked to health and well-being, whereas political action sometimes shows negative associations with wellbeing (Ballard et al., 2019; Wray-Lake et al., 2019). Yet, recent research found that increased prosocial behaviors during COVID-19 were associated with poorer adolescent mental health (Alvis et al., 2020), with youth potentially seeking opportunities to help others as a form of coping with the pandemic. Youth may gravitate to civic activities in part depending on their demographic characteristics. Girls tend to engage in more helping behaviors, whereas some studies find that boys engage in more political action (Cicognani et al., 2012). Youth from higher-SES backgrounds tend to participate more in helping and political activities (Gaby, 2017). Findings are mixed regarding racial/ethnic differences in youth civic engagement, and race/ethnicity may intersect with gender and SES to inform civic engagement (Wray-Lake et al., 2020). Summer 2020 brought increased protests of racial injustice in the U.S., youth of color may have participated in more online political action compared to other groups. Youth of color as well as LGBTQ youth may be drawn to political action as a way to cope with and resist stressors of marginalization (Hope et al., 2020; Poteat et al., 2018).

\section{Adolescents' Work}

Historically, about half of U.S. adolescents spent their summers working paid jobs, although this proportion declined to less than 35\% in 2018, due to the economic recession (Pew Research Center, 2019). Employment opportunities have dramatically declined during the COVID-19 pandemic; in July, 2020, 31.3 million Americans reported job loss or fewer work hours as a result of COVID-19 (U.S. Bureau of Labor Statistics, 2020). Thus, we might expect few adolescents to be employed during summer 2020, but working may be an important way that 
adolescents contribute to household income or respond to heightened economic stressors. Research has documented benefits and risks of adolescents' part-time work, depending on its duration, quality, and youth's goals and motivations (Mortimer, 2010). In national U.S. samples during non-pandemic times, White youth and lower-SES youth are more likely to report paid work during the school year (Bachman et al., 2013). During COVID-19, adolescents' employment substantially heightens exposure to and risk of contracting the coronavirus, yet may also offer adolescents opportunities for social interaction with peer co-workers and employers. Beyond work for pay, adolescents engage in chores, childcare, and other housework to contribute to their families. Asian and Latinx adolescents report stronger family expectations to complete household chores and help out at home than White adolescents (Fuligni et al., 2009), and girls and Black youth tend to report more time doing housework (Gager et al., 2009).

\section{Self-Improvement Activities}

During COVID-19, adolescents may be spending time on self-improvement in activities that offer outlets for skill development, positive coping, and health promotion. Adolescents who spend the summer on educational activities may be focused on learning or practicing new skills or future goals like attending college (Shanahan \& Flaherty, 2001). Engagement in educational activities during COVID-19 has been linked to lower loneliness for adolescents (Ellis et al., 2020). Adolescents with more educated parents may be encouraged to spend more time on educational activities (Gracia et al., 2020). Physical exercise is a health behavior that improves adolescents' cardiovascular health and cognitive functioning and reduces depressive symptoms (Biddle et al., 2019). Boys tend to spend more time on physical activity and in sports (Garton et al., 2004). Religious and spiritual practices can also be outlets for coping during stressful times, and adolescents' spiritual practices have been positively linked to well-being (Hardy et al., 
2019). Religious practices may vary by race/ethnicity; for example, Black adolescents report higher rates of church attendance on average than White youth (Smith et al., 2002). Arts and music may also be expressive outlets for thoughts and feelings during the pandemic (Schwan et al., 2018) and relate to self-esteem and self-confidence (Bungay \& Vella-Burrows, 2013).

\section{Time with Family and Friends}

Spending time with family and friends is an important component of adolescents' daily lives (Updegraff et al., 2006). Given stay-at-home orders during COVID-19, U.S. adolescents may be spending more time with family and less time with friends. Adolescents who spent more time with their family during COVID-19 had lower levels of depression and loneliness (Ellis et al., 2020). Other adolescents may choose time with friends virtually or via text as a source of connection and coping during COVID-19. However, adolescents who spent more time virtually with peers during COVID-19 reported higher depression (Ellis et al., 2020). Leisure time with family and friends may vary by race/ethnicity: One study found that Chinese immigrant youth were less likely to spend leisure time with family compared to Mexican immigrant youth (Hardaway \& Fuligni, 2006). Relationship quality with parents and friends likely plays an important role in how much time adolescents choose to devote to family or friends during the pandemic. More broadly, family and peer contexts are key ecologies that may shape adolescents' choices about daily activities during the pandemic, a topic to which we now turn.

\section{Family and Peer Relationships and Adolescent Time Use}

Families and peers comprise two of the most central contexts for adolescent development. Considering both family and peer contexts in relation to adolescents' time use can lead to a more informed understanding of adolescents' social ecology and highlight potential relational factors that shape adolescents' time use during COVID-19. During adolescence, youth 
increasingly spend more time with friends and less time with family (De Goede et al., 2009). However, this normative developmental trend may have shifted abruptly and dramatically during COVID-19, causing U.S. adolescents to spend much more time with family and little time with friends. We seek to determine the implications of family and peer relationships for adolescents' time use, proposing that adolescents' choice of activities to cope with COVID-19 may depend on the degree and type of support they have from parents and friends. This idea aligns with time use theories that adolescents will choose activities that offer positive experiences and withdraw from contexts that offer negative experiences (Shanahan \& Flaherty, 2001). Although our crosssectional study cannot assess directions of effect, it is also plausible that when adolescents select certain activities, these choices change the ways their parents and friends support them.

Support from parents is widely understood to protect against adolescents' risk behaviors and promote adolescents' well-being (Barnes et al., 2006; Klineberg et al., 2006). Family support during disasters is important for young people's mental health and wellbeing (Masten \& Narayan, 2012), indicating that family support may be even more crucial during COVID-19. Family support may encourage adolescents to spend time on self-improvement activities, as adolescents with supportive parents are found to spend more time on religious activities (Good et al., 2009; Linver et al., 2009), physical activity (Casey et al., 2016), academics (Malczyk \& Lawson, 2017), and school and communities more broadly (Metzger et al., 2009). Adolescents whose parents are supportive are also more likely to choose to spend time with family (Crouter et al., 2004). Thus, parent support may encourage adolescents to choose healthy coping strategies or stay engaged in various activities during challenging times. In contrast, family time during COVID-19 was negatively correlated with social media use (Ellis et al., 2020), and social media use is often a point of contention between adolescents and parents (Blackwell et al., 2016). 
COVID-19 is undoubtedly a crisis of epic proportions that families around the world are experiencing to varying degrees. Nearly half of U.S. households are facing serious financial difficulties and almost $60 \%$ of parents report significant challenges in caring for children during COVID-19 (NPR, 2020), which may increase family conflict. To the extent they are able, adolescents may reduce the amount of time they spend with family in response to conflict (Crouter et al., 2004), and family conflict instead may prompt them to spend time in other ways. Higher family conflict and stressors have been associated with adolescents spending more time on housework and chores (Gager et al., 2009), less time on homework (Bang, 2011), less time on physical activity (Iannotti et al., 2009), less time on prosocial behaviors (Silke et al., 2018), more time on computer and television use (Lee et al., 2009; Sela et al, 2020), and more time on the internet and playing video games (Bonnaire \& Phan, 2017; Wu et al., 2016). In some cases, family conflict may result from adolescents' time use; for example, parents' directives to spend time on housework, adolescents' lack of time on homework, or adolescents' high investment in video games may heighten family conflict. Family conflict may drive youth to online spaces, where they feel freedom from parents and ability to openly express themselves (Rickman, 2020).

Two distinct models attempt to explain the interplay between parents and peers in the lives of adolescents (Cooper et al., 1992; Wilkinson, 2004). According to continuity models, which are rooted in attachment theory, peer relationships are an extension of the kinds of relationships adolescents developed with parents, such that adolescents with higher support from parents also have supportive friendships. Adolescents have been found to draw on support from multiple sources including parents and friends in dealing with challenges (Johnson et al., 2011), and adolescents who have secure, supportive relationships with their parents are more likely to have supportive friendships (Brown \& Bakken, 2011). Compensatory models, on the other hand, 
posit that adolescents seek from friends what they cannot get from parents. In line with this model, much existing research emphasizes tensions between family and peer domains of influence, suggesting that parents play a protective or gate-keeping role in adolescents' peer relationships (Tilton-Weaver \& Galambos, 2003), and that parent influence on adolescents' daily lives declines across adolescence while peer influence increases (Nickerson \& Nagle, 2005). Adolescents who feel low support or high conflict with parents may turn to peers for support (del Valle et al., 2010), and in these cases, friends can serve as a protective factor against depression and anxiety (Roach, 2018). We investigated the role of parent-child relationships and friendships in relation to adolescents' time use, recognizing that parent and friend support may have similar or divergent relationships with time use profiles.

Peer support has been associated with adolescents' time use in ways similar to family support. For instance, friends' support has been positively linked with adolescents' time spent in structured extracurricular activities (Huebner \& Mancini, 2003), civic participation (Da Silva et al., 2004) and school engagement (Berndt \& Keefe, 1995), whereas peer rejection has been associated with disengagement from school and structured activities (Buhs et al., 2006; Denault \& Pulin, 2009). Compensatory processes may emerge when considering social media use. Whereas family support and interactions tend to be related to less social media use during COVID-19, adolescents may be spending more time online and on social media to connect with and receive support from friends (Ellis et al., 2020). For adolescents who go online to nurture existing friendships, social media usage is related to higher perceived social support and selfesteem (Valkenburg \& Peter, 2007). Conflicts with parents during COVID-19 may drive adolescents to spend more time with friends online to find peer support.

\section{Methodological Considerations}


Accurately modeling adolescents' time use requires the ability to characterize variability in complex patterns of activities that co-occur in a typical day (Ferrar et al., 2013). Personcentered approaches such as LPA can categorize individuals based on similarities in time use and thus provide an important conceptual advantage to studying time use. Person-centered analyses use a data-driven approach to identifying typologies, and the novelty COVID-19 calls for an exploratory, person-centered approach to shed light on the complex ways youth are spending their time to help inform future research and theory concerning the impact of the pandemic on adolescent development. Given that the nature of time use profiles are not known in advance, we cannot propose specific confirmatory hypotheses about how demographics or parent support, parent conflict, or friend support relate to profiles. Rather, our approach embraces the novelty of social life during the COVID-19 pandemic and the exploratory nature of person-centered data analytic techniques, while contextualizing our study questions and results in past research.

\section{Current Study}

This study aimed to explore how US adolescents spent their time in summer 2020 during COVID-19 and test variation in time use by demographic characteristics, parent-adolescent conflict, parent support, and friend support. We utilized latent profile analysis to identify patterns of time use across 14 different activities focused on work and leisure. Beyond expecting that some adolescents are spending large quantities of time using media (Ellis et al., 2020), we had no expectations of what profiles would emerge to capture adolescents' time use during COVID-19. We explored differences in adolescents' time use profiles by gender, race/ethnicity, parent education (a marker of SES), and sexual orientation, as different youth may be facing different realities at home and adapting to COVID-19 in different ways. Examining parent-adolescent conflict, parent support, and friend support as predictors of adolescents' time use profiles may 
point to compensatory processes, given a current tension between heightened time with family and challenges to seeing friends. We also included in-person time spent with friends as a predictor of profiles to gain more insight into differences in peer dynamics across groups.

\section{Method}

\section{Participants}

Participants were 555 adolescents residing in the United States, between the ages of 12 and 21 years $(M=16.28, S D=1.29)$. The sample was primarily $12^{\text {th }}(29.4 \%), 11^{\text {th }}(23.8 \%)$, and $10^{\text {th }}$ graders $(18.2 \%)$, with fewer $9^{\text {th }}$ graders $(7.39 \%)$, and had more females $(49.6 \%)$ than males (39.7\%), with $7.9 \%$ identifying as non-binary. In terms of race/ethnicity, the sample was nonHispanic White (47.2\%), Latinx (19.6\%), Asian (17.5\%), Black (7.2\%), American Indian/Alaska Native (5.0\%) and another race/ethnicity (2.9\%). Most adolescents' parents had at least a college degree $(56.1 \%$ of mothers; $54.3 \%$ of fathers). Youth identified as straight/heterosexual (47.2\%), lesbian/gay/bisexual/queer (27.0\%), and unsure/questioning or as having multiple identities $(25.8 \%)$. Youth reporting straight and another sexual orientation were coded as not straight.

The study was advertised to teenagers on Instagram and participants self-selected to complete a 10-minute survey. Data were collected from August 5th, 2020 to August 28th, 2020. This study involved no more than minimal risk, and thus, a waiver of parent permission was granted. Upon selecting into the study, participants were given a link to a letter explaining the study and asked to provide this letter to their parents informing them of their participation. Youth provided informed written consent before continuing to the survey. Participants were entered into a drawing for a \$50 Amazon gift card. This study protocol was approved by the institutional review board at [INSTITUTION BLINDED FOR REVIEW].

\section{Measures}


Time Use. Adolescents were asked to think about a typical day in the past week and indicate which of 14 activities they engaged in on a typical day. For activities they reported engaging in, they were then asked how long they spent on the activity by selecting discrete responses of hours (from 0 to $5+$ hours) and minutes (from 0 to 50 , in intervals of 10 minutes). Activities included work (work for pay; doing chores, childcare or other family work); media use (spending time on social media, watching shows or movies, playing video games); social interactions (time with family; interacting with friends online or via phone/text); selfimprovement (educational activities; working out or exercising; engaging in religious, spiritual, or meditation activities; creating art or music); and civic engagement (helping others; engaging in online political action; watching or reading the news). Activity categories were selected to capture various ways youth may spend their waking time during the pandemic, and are similar to time use measures in other studies (e.g., Shanahan \& Flaherty, 2001). We utilized a stylized approach to measuring time use, rather than comprehensive time diary methods (Hunt et al., 2015), to document adolescents' time use across several key domains that reflect coping and link to well-being. Selecting a limited number of activities greatly reduces participants' response burden compared to other methods, which was important in surveying youth during a pandemic. Items were recoded to reflect the amount of time in hours youth spent engaging in each activity.

Parent-adolescent conflict. Parent-adolescent conflict was measured with 3 items ( $\omega=$ $.87 ; \lambda$ 's range $=.83$ to .86 ). Adolescents indicated the frequency of conflict with their parents (e.g. "had a serious argument or fight"; Yuen et al., 2018). Responses were provided on a 6-point scale: not at all (1), once or twice (2), about once a week (3), several times a week (4), every day (5), and multiple times a day (6). Higher values indicate higher parent-adolescent conflict.

Parent and friend support. Youth reported on past month general parent support (3 
items; e.g. "how often have your parents shown that they care about you") and positive social exchange with parents ( 3 items; e.g. "how often have you done an activity together to help get your mind off of things") using items from the Inventory of Socially Supportive Behaviors (Finch et al., 1997). The same six items assessed past month friends' general support and positive social exchange by replacing parents with friends. Responses were provided on a 6-point scale: not at all (1), once or twice (2), about once a week (3), several times a week (4), every day (5), and multiple times a day (6). A confirmatory factor analysis indicated that support and positive social exchange latent variables were very highly correlated and inseparable for parents $(r=1.00)$ and friends $(r=.89)$, and thus items were modeled as a single latent construct for parents and friends, respectively. For model parsimony, three parcels were created that averaged a support with an exchange item (Little, 2013); factor loadings and omega coefficients indicated construct validity and internal reliability, respectively for parent $(\lambda$ 's range $=.73$ to $.86 ; \omega=.83$ ) and friend support ( $\lambda$ 's range $=.80$ to $.89 ; \omega=.84$ ). Higher values indicate higher support.

In-person time with friends. Adolescents reported time spent with friends in person in the past month with a single item: "In the past month, how often have you spent time with friends in person?". Responses were provided on a 6-point scale: not at all (1), once or twice (2), about once a week (3), several times a week (4), every day (5), and multiple times a day (6). Higher values indicated more in-person time with friends. This variable was used as a predictor of time use profiles, rather than an indicator of profiles, as it was not measured in hours. We expected in-person contact with friends to offer insight into adolescents' peer contexts.

Demographic covariates. Adolescents reported their gender, race/ethnicity, parent education, and sexual orientation. Gender was dummy-coded into male, female, and non-binary. Race/ethnicity was dummy coded into White, Asian, Latinx, and other. Due to small sample 
sizes, Black, American Indian, and other races were coded as other, and results with this group are not interpreted. For sexual orientation, adolescents were dummy-coded as LGBQ (lesbian, gay, bisexual, and queer or questioning) and straight. Due to small sample sizes and lack of specific hypotheses, we retained these broad categories for LGBQ identity. Parents' education was computed as the average of youth reports of mothers' and fathers' education (where applicable) as separate items on a 3-point scale, including high school or less (1), some college (2), and college graduate or more (3). Responses indicating "don't know" were coded as missing. Higher scores indicate higher education attainment.

\section{Analytic Plan}

To identify latent subgroups of time use among adolescents, we used latent profile analysis based on the 14 time use indicators, which were continuous variables measured in hours. Class enumeration based on prior research, analytic utility, and model fit from solutions that specified one to four classes. Bayesian Information Criterion (BIC), Akaike's Information Criterion (AIC), Lo-Mendell-Rubin likelihood ratio test (LMR-LRT), bootstrap likelihood ratio test (BLRT), the analytic utility of class sizes, and entropy were used to evaluate model fit. Low BIC and AIC and high LMR-LRT/BLRT values indicate better model fit (Nylund et al., 2007). A significant $p$-value for the BLMR-LRT/BLRT indicated that the current class solution provided a better model fit than a solution with one fewer class. Solutions with a class size less than $5 \%$ of the sample were not considered viable. Once class enumeration was established, latent profiles were classified into discrete, mutually exclusive groups. Hard classification enabled the use of latent variable predictors and FIML to handle missing data. Multinomial logistic regression was then used to examine demographics, parent-adolescent conflict, parent support, friend support, and in-person friend contact as predictors of time use profile membership. Demographic 
characteristics and in-person contact with friends were manifest independent variables and parent-adolescent conflict and parent and friend support were latent variables. Missing data were estimated using FIML. We used a three-form planned missing design for items contributing to latent variables; each participant randomly completed 2/3rds of each latent variable item set. Planned missing designs reduce burden on participants, and planned missing data are missing completely at random (MCAR; Little \& Rhemtulla, 2013). Item non-response was higher for parent education $(<4.5 \%)$, but lower for other variables $(1.0 \%)$.

\section{Results}

\section{Descriptive Statistics and Bivariate Correlations}

Table 1 displays means, standard deviations, and bivariate correlations among study variables. Adolescents spent the most time on social media $(M=2.41$ hours, $S D=1.67)$, watching shows or movies $(M=2.23, S D=1.59)$, and interacting with friends via phone/text $(M$ $=2.22, S D=1.75)$. They spent the least time engaging in online political action $(M=0.36$ hours, $S D=0.79)$, helping others $(M=0.41, S D=0.87)$, and watching or reading the news $(M=0.56$, $S D=0.87$ ). Regarding relationships with parents and friends, parent support was positively correlated with friend support and in-person contact with friends, but negatively correlated with parent conflict. Friend support was positively correlated with in-person time with friends.

Regarding time use, parent support was positively related to spending time with family, working out or exercising, and engaging in religious, spiritual, or meditation activities. Parent support was negatively correlated with playing video games, watching shows or movies, interacting with friends online or via phone/text, spending time on social media, engaging in online political action, and creating art or music. Parent-adolescent conflict was positively correlated with watching shows or movies, interacting with friends online or via phone/text, 
spending time on social media, helping others, engaging in online political action, and creating art or music. Parent-adolescent conflict negatively correlated with spending time with family, working out or exercising, and engaging in religious, spiritual, or meditation activities. Friend support was positively correlated with interacting with friends online or via phone/text, spending time on social media, and helping others. In-person time with friends positively correlated with working for pay, engaging in religious, spiritual, or meditation activities, and helping others and negatively related to playing video games and doing chores, childcare, or other family work.

Regarding demographics, identifying as female was positively correlated with parent support, while identifying as non-binary or LGBQ was negatively correlated with parent support and positively correlated with parent conflict. In-person time with friends was negatively correlated with identifying as Latinx and positively correlated with parents' education.

\section{Latent Profiles of Adolescent Time Use during COVID-19}

Table 2 presents model fit and comparisons for latent profile solutions for 1 to 4 classes. We selected a 3-class solution as the optimal model for our data. The lower BIC and AIC and the LMR-LRT/BLRT comparisons confirmed that the 3-class solution was a significantly better fit than the 2-class solution. The 4-class solution showed lower BIC and AIC, and significant improvement based on LMR-LRT/BLRT comparisons; however, two of the four classes had very small sample sizes ( $n=22$ and $n=16$ ). Thus, the 3 -class model was selected due to fit and utility, with acceptable entropy (.89).

Figure 1 presents the average time spent in each activity by class membership. Class 1 ( $n$ $=267 ; 48.2 \%$ of sample) was labeled Education-Focused and was characterized by more time spent on educational activities on a typical week in the summer compared to others $(M=1.83$ hours, $S D=0.13)$. Education-Focused youth also spent less time interacting with friends online 
or via phone/text $(M=1.38, S D=0.10)$ and on social media $(M=1.37, S D=0.09)$ compared to others. Class 2 ( $n=166,30.0 \%$ of sample) was labeled Media Users and was characterized by more time spent interacting with friends online or via phone/text $(M=3.54, S D=0.17)$, on social media $(M=4.16, S D=0.12)$, watching shows or movies $(M=2.89, S D=0.14)$, playing video games $(M=1.92, S D=0.16)$, on online political action $(M=0.74, S D=0.10)$, and watching or reading the news $(M=0.75, S D=0.10)$ compared to other groups. Interestingly, Media Users also spent more time creating music or art $(M=0.99, S D=0.12)$ and slightly more time on chores, childcare, or other family work $(M=1.20, S D=0.11)$. Class $3(n=121,21.8 \%$ of sample) was labeled Workers and was characterized by high hours spent working for pay $(M=$ 4.61, $S D=0.06$ ), compared to very little time working for pay among other groups. Time spent across other activities including interacting with family, helping others, exercising, and on religious/spiritual practices did not distinguish between classes.

\section{Demographic and Relational Differences in Latent Profiles}

Two multinomial logistic regressions examined parent support, friend support, parentadolescent conflict, in-person contact with friends, and demographic characteristics as predictors of profile membership. The Workers class was specified as the reference group in the first model and the Education-Focused class was specified as the reference group in the second model to compare all three groups. See Table 3 for the full set of results.

Regarding demographic differences in adolescents' time use profiles, Education-Focused adolescents were less likely to be female $(O R=0.59[0.39-0.87])$ compared to Workers. Media Users were more likely to be female compared to the Education-Focused adolescents $(O R=$ 1.93[1.30-2.86]). Media Users were also more likely to identify as LGBQ compared to Education-Focused adolescents $(O R=2.02[1.37-2.96])$. Race/ethnicity and parents' education 
were not significantly associated with profile membership.

Figure 2 displays raincloud plots for parent support, parent conflict, friend support, and in-person time with friends by latent profile. Education-Focused adolescents reported higher parent support compared to Workers $(O R=1.49[1.15-1.92])$. Media Users reported lower parent support $(O R=0.57[0.44-0.74])$ than Education-Focused adolescents. Media Users and Workers did not differ on parent support. There were no statistically significant differences in reported parent-adolescent conflict between the time use profiles.

For friend support, Education-Focused adolescents reported lower friend support compared to Workers $(O R=0.73[0.57-0.95])$. Media Users also reported higher friend support compared to Education-Focused adolescents $($ OR $=1.84[1.45-2.34])$. Media Users and Workers did not differ on friend support. Compared to Workers, Education-Focused adolescents $($ OR $=$ $0.76[0.64-0.91])$ and Media Users $(O R=0.65[0.53-0.79])$ spent less time in-person with friends.

\section{Discussion}

Our study identified three distinct typologies of adolescents' time use during the COVID19 pandemic. Education-focused, media use, and work-focused profiles indicated that youth are having very different daily life experiences during this unique crisis point in history. At a time when typical developmental opportunities through work, extracurricular, and leisure activities have been abruptly limited or cancelled for adolescents, the three time-use profiles show that adolescents have found different ways to adapt to these challenging circumstances. Adolescents' choice of activities differed systematically based on gender and sexual orientation as well as their levels of support from parents and friends. By examining associations between adolescents' time use, their sociodemographic characteristics, and relational contexts, our study suggests that each profile of adolescents exhibits some strengths and vulnerabilities, which has implications for 
theories of family and peer support and for adolescents and families during times of crisis.

\section{Education-Focused Youth}

Youth classified as education-focused in our study spent over twice as much time on educational activities as other youth and spent modest amounts of time across other activities compared to their peers. These youth had a greater likelihood of being male and reported higher support from parents and lower support from friends, compared to their counterparts. The higher family support experienced by these adolescents may be due multiple co-occurring dynamics and relational processes. When adolescents feel more supported by parents, they may be more likely to change their behaviors in response to parents' input, guidance, or rule-setting (e.g., Keijsers et al., 2009). Parents and adolescents in these families may be following recommendations from educators to avoid the "summer melt" and maintain academic engagement and learning (Castleman \& Page, 2014), advice that may be especially important when many U.S. adolescents have fallen behind grade-level standards or begun to struggle academically due to the abrupt shift to remote learning (Kuhfeld et al., 2020). Another possibility is that parent support and positive exchanges may encourage adolescents to seek a range of stimulating activities during a typical day, including education. Past research supports this idea in documenting that adolescents with lower parent support were uninvolved across a range of different extracurricular, work, and leisure activities, whereas youth who reported more parent support were more engaged across activities (e.g., Metzger et al., 2009). Alternatively, youth who show initiative and focus on educational pursuits may please their parents, who in turn offer them more support and encouragement (Benner et al., 2016). Overall, it seems that these youth are engaging in a balance of activities and finding strength in supportive parent relationships.

However, education-focused youth reported lower support from friends, which suggests 
some vulnerability in their lived experiences during the pandemic, as adolescent friendships are important for self-confidence, identity development, and psychological well-being (Furman \& Rose, 2015). This pattern of findings aligns with a compensatory model of parent and peer relationships (Cooper et al., 1992; Wilkinson, 2004) in their reporting of high parent support and low friend support. To the extent that adolescents with supportive parent relationships are choosing not to nurture friendships or are restricted from spending time on phones or social media, their lower time spent on these activities may reduce opportunities to connect with friends. These restrictions may be especially difficult during the COVID-19 pandemic, as spending time with others in person carries heightened personal health risks. Boys were also more likely to be in the education-focused group. Boys are often socialized to have less close friendships (Way, 2011) and may have difficulty sustaining friendships without in-person contact. An alternative compensatory explanation for these findings is that education-focused youth may be getting the support they need from parents, making them less apt to seek out or nurture friendships. These ideas merit more explicit testing through longitudinal designs and use of other kinds of statistical models to determine whether low social media use and high parent support predict declines over time in friend support during COVID-19.

\section{High Media Users}

Youth classified as media users in our study were engaged in very high levels of screen time across watching shows and movies, playing video games, and spending time on social media. Although national estimates prior to the pandemic already suggested high levels of screen time for U.S. adolescents (Rideout \& Robb, 2019), social media use may be on the rise among adolescents during COVID-19 (Ellis et al., 2020). Notably, a portion of these youth's media time focused on relationship seeking via chatting or texting with peers and engagement in social 
issues through news watching or online political action. These youth also spent more time creating art or music than other youth, and online spaces are often contexts for these kinds of creative expressions (Shresthova, 2013). Thus, these youth are likely engaged in a combination of passive viewing and highly active participation in social and community life.

The media users group was more likely to be composed of LGBQ-identifying youth, which is important to consider in concert with findings that media users reported lower support from parents and higher support from friends. Sexual minority adolescents may be feeling isolated, misunderstood, or marginalized by their families. Likewise, past studies have found lower parent support and acceptance and greater parent avoidance, neglect, and abuse of sexual minority adolescents (Friedman et al., 2011). These patterns may be exacerbated during the COVID-19 pandemic, when many adolescents must stay at home and interact more with families, some of whom may not be supportive of their sexual orientation (Cohen \& Bosk, 2020). For youth who feel marginalized, social media may provide avenues for building community and strengthening social connections (Ybarra et al., 2015). Indeed, media users reported higher support from friends. Thus, although many education and health professionals warn against health risks of screen time - including high media consumption, social media time, and video gaming (Kelly et al., 2018; Twenge et al., 2018) - our results suggest that media use during COVID-19 may provide important spaces for friendship, support-seeking, and coping for sexual minority adolescents (Orben et al., 2020). Again, the pattern of low parent support and high friend support for this group suggest compensatory processes at play in family and peer domains. Low family support may be driving youth online to seek greater support from friends. Alternatively, high media use and time spent connecting with friends virtually may decrease opportunities for support and positive exchanges with parents. 


\section{Working Youth}

Around $20 \%$ of our sample spent time working for pay during the COVID-19 summer of 2020, and these youth were more likely to be female and to report spending time in-person with friends. We presume that these youth are engaged in part-time work outside the home, which is common for adolescents in non-pandemic times (Pew Research Center, 2019), but during COVID-19, part-time work significantly heightens adolescents' risks of contracting and spreading the coronavirus. Although the prevalence of COVID-19 cases and associated risks vary across the U.S., August 2020 had peak numbers of cases in the U.S. and new cases across all 50 states (WHO, 2020). Work may also be a way that adolescents are contributing to their families or mitigating economic stressors during the pandemic. Adolescent girls, in particular, may be working as a way to help family or others during the COVID-19 pandemic, as girls are more likely than boys to engage in selfless forms of prosocial behavior (Carlo et al., 2003) and girls have exhibited more prosocial behavior than boys during the pandemic (Alvis et al., 2020). Our findings highlight the potentially challenging trade-offs for working youth who may experience heightened stress due to increased possible exposure to the virus, while at the same time, work may afford opportunities to meet economic needs and connect with friends and others in-person. Some youth may be following social distancing and mask-wearing guidelines when working and spending in-person time with friends, while others may not be following recommendations. Working youth in our sample were not found to be distinct on parent or friend support, suggesting no vulnerabilities on these dimensions.

\section{Limitations}

Findings from this study should be interpreted in the context of certain limitations. The study design was cross-sectional and causal or temporal claims can not be made. Future 
longitudinal studies are needed to examine the temporal sequencing between time use, family relationships, and peer relationships during COVID-19. Although the sample varied in race/ethnicity and sexual orientation, participants were recruited using social media, which may have been prone to selection bias. We may have also oversampled youth who spend time on platforms like Instagram and missed capturing experiences of youth not on social media. Future research should replicate these findings using samples recruited through diverse mediums, such as schools. Our time use measures did not assess substance use, which is commonly studied in other research on adolescents' time use (e.g. Iannotti et al., 2009). We did not take a comprehensive approach to assessing time use, and thus, we may be missing others ways that adolescents are coping with the pandemic. Further, a central goal of this study was to examine adolescents' time use and social relationships during the COVID-19 pandemic, a global event that was thought to have produced notable disruptions to these processes. However, other national events - such as the Black Lives Matter movement and upcoming US national election may have also produced period effects in these results. Future research would benefit from examining the complex intersection between these period effects to gain a more complete understanding of their influence on adolescent development.

\section{Implications for Theory and Research}

Our study demonstrates that adolescents are adapting to the COVID-19 pandemic in ways that map onto their demographic factors and relational contexts. Studying time use offers insight into adolescents' lived experiences and has important implications for adolescents' health and well-being (Ferrar et al., 2013). Our study suggests that adolescents' time use should be continually reassessed, as changing dynamics during health crises or other major events may shift adolescents' social, leisure, and enrichment opportunities and change what different kinds 
of time use mean for their health and well-being. Additionally, the types of support adolescents receive from parents and friends has important implications for the ways in which adolescents spend their time during a national health crisis. Our results support a pattern of compensatory processes between family and peer relationships in demonstrating opposing roles of parent and friend support for both the media use and education-focused groups. Many youth during the pandemic may be facing very tangible trade-offs between parent and friends' support, especially at a time when youth lack access to many of the contexts through which adolescents naturally interact in-person with peers and spend time away from parents. An implication for theory is that this health crisis, with its dramatic social implications, may be uniquely creating competing dynamics between peers and parents for adolescents to navigate. Moreover, the effects of the COVID-19 pandemic on relational dynamics and adolescents' time use may be long-lasting through establishing new patterns of support giving or seeking or new habits of time use among adolescents. Supports that youth do or do not receive from parents and friends during the COVID-19 pandemic may also cascade to academic functioning, health, or well-being over time.

Perhaps surprisingly, we did not find associations between parent-adolescent conflict and adolescent time use profiles. Parent conflict was bivariately related to hours spent across various activities, and appeared to be a valid and reliable measure. Perhaps parent conflict and support, despite their modest negative correlation, predicted overlapping variance in time use profiles. Additional research might examine mediation, moderation, or cross-lagged models using longitudinal data to more comprehensively explore processes by which parent conflict and support relate to adolescents' time use during COVID-19.

\section{Implications for Practice and Policy}

Parents are undoubtedly seeking insight into healthy ways for adolescents to spend time 
during the COVID-19 pandemic. Each of the time use profiles we identified suggest different risks to health or well-being, which is unfortunate but fitting for lived experiences during a global health crisis. Education-focused youth reported low support from friends, high media users had low family support, and youth who work may be putting themselves at greater risk for contracting the virus. Yet, each group also showcased strengths: Education-focused youth were pursuing learning and feeling supported by parents, high media users experienced support from friends and were more engaged in civic contributions and creative arts, and working adolescents were having in-person contact with friends, which can meet important needs for connection. Parents and others should engage youth in open conversations about their challenges during the pandemic, which may help identify ways to strengthen relational supports and mitigate risks for different groups of youth. As the pandemic continues it is important to pursue conversations with adolescents about how they can best be supported during these challenging times. We also underscore the conclusion from other research that parents must find ways to show love and support for their LGBQ children (Russell \& Fish, 2016).

Our findings raise the need to consider where and how youth receive social support and can inform debates regarding adverse or advantageous effects of adolescent screen time (e.g., Twenge et al., 2018). Our results show that screen time may pose some meaningful advantages to youth, especially when face-to-face interactions are limited. These findings emphasize the need to further understand how youth are using online media rather than focusing only on the amount of time using media (Orben \& Prybensky, 2019), and may call for health policymakers, medical practitioners, and others to consider more flexible or nuanced recommendations about media use for adolescents during the pandemic. Policies should also continue to ensure that workplaces are safe for adolescents and that proper precautions are being followed to minimize 
risks for teens and workers of all ages. Schools - whether in-person or remote - should consider how to meet adolescents' needs for support and connection and integrate services for health and well-being into core practices. Communities should devote concerted attention and resources to rebuilding or reimagining opportunities for adolescents' time use during the pandemic that prioritize safety, social connection, and well-being. 


\section{References}

Alvis, L., Shook, N., \& Oosterhoff, B. (2020). Adolescents' prosocial experiences during the covid-19 pandemic: Associations with mental health and community attachments. Retrieved from: https://psyarxiv.com/2s73n.

Bachman, J. G., Staff, J., O'Malley, P. M., \& Freedman-Doan, P. (2013). Adolescent work intensity, school performance, and substance use: Links vary by race/ethnicity and socioeconomic status. Developmental psychology, 49(11), 2125.

Ballard, P. J., Hoyt, L. T., \& Pachucki, M. C. (2019). Impacts of adolescent and young adult civic engagement on health and socioeconomic status in adulthood. Child Development, 90(4), 1138-1154.

Bang, H. J. (2011). Newcomer immigrant students' perspectives on what affects their homework experiences. The Journal of Educational Research, 104(6), 408-419.

Barnes, G. M., Hoffman, J. H., Welte, J. W., Farrell, M. P., \& Dintcheff, B. A. (2007). Adolescents' time use: Effects on substance use, delinquency and sexual activity. Journal of Youth and Adolescence, 36(5), 697-710.

Bartko, W. T., \& Eccles, J. S. (2003). Adolescent participation in structured and unstructured activities: A person-oriented analysis. Journal of Youth and Adolescence, 32(4), 233-241.

Benner, A. D., Boyle, A. E., \& Sadler, S. (2016). Parental involvement and adolescents' educational success: The roles of prior achievement and socioeconomic status. Journal of Youth and Adolescence, 45(6), 1053-1064.

Berndt, T. J., \& Keefe, K. (1995). Friends' influence on adolescents' adjustment to school. Child Development, 66(5), 1312-1329.

Best, P., Manktelow, R., \& Taylor, B. (2014). Online communication, social media and adolescent wellbeing: A systematic narrative review. Children and Youth Services Review, 41, 27-36.

Biddle, S. J., Ciaccioni, S., Thomas, G., \& Vergeer, I. (2019). Physical activity and mental health in children and adolescents: An updated review of reviews and an analysis of causality. Psychology of Sport and Exercise, 42, 146-155.

Blackwell, L., Gardiner, E., \& Schoenebeck, S. (2016, February). Managing expectations: Technology tensions among parents and teens. In Proceedings of the 19th ACM Conference on ComputerSupported Cooperative Work \& Social Computing (pp. 1390-1401).

Boer, M., van den Eijnden, R.J., Boniel-Nissim, M., Wong, S.L., Inchley, J.C., Badura, P., Craig, W.M., Gobina, I., Kleszczewska, D., Klanšček, H.J. and Stevens, G.W. (2020). Adolescents' intense and problematic social media use and their well-being in 29 countries. Journal of Adolescent Health, 66(6), S89-S99. 
Bonnaire, C., \& Phan, O. (2017). Relationships between parental attitudes, family functioning and Internet gaming disorder in adolescents attending school. Psychiatry Research, 255, 104-110.

Brown, S. M., Doom, J. R., Lechuga-Peña, S., Watamura, S. E., \& Koppels, T. (2020). Stress and parenting during the global COVID-19 pandemic. Child abuse \& neglect, 104699.

Brown, B. B., \& Bakken, J. P. (2011). Parenting and peer relationships: Reinvigorating research on family-peer linkages in adolescence. Journal of Research on Adolescence, 21(1), 153-165.

Bucksch, J., Sigmundova, D., Hamrik, Z., Troped, P.J., Melkevik, O., Ahluwalia, N., Borraccino, A., Tynjälä, J., Kalman, M. and Inchley, J. (2016). International trends in adolescent screen-time behaviors from 2002 to 2010. Journal of Adolescent Health, 58(4), 417-425.

Buhs, E. S., Ladd, G. W., \& Herald, S. L. (2006). Peer exclusion and victimization: Processes that mediate the relation between peer group rejection and children's classroom engagement and achievement? Journal of Educational Psychology, 98, 1-13.

Bungay, H., \& Vella-Burrows, T. (2013). The effects of participating in creative activities on the health and well-being of children and young people: a rapid review of the literature. Perspectives in Public Health, 133(1), 44-52.

Casey, M., Harvey, J., Telford, A., Eime, R., Mooney, A., \& Payne, W. (2016). Patterns of time use among regional and rural adolescent girls: associations with correlates of physical activity and healthrelated quality of life. Journal of science and medicine in sport, 19(11), 931-935.

Castleman, B. L., \& Page, L. C. (2014). A trickle or a torrent? Understanding the extent of summer “melt" among college- intending high school graduates. Social Science Quarterly, 95(1), 202-220.

Cicognani, E., Zani, B., Fournier, B., Gavray, C., \& Born, M. (2012). Gender differences in youths' political engagement and participation. The role of parents and of adolescents' social and civic participation. Journal of Adolescence, 35, 561-576.

Cohen, R. I. S., \& Bosk, E. A. (2020). Vulnerable youth and the COVID-19 pandemic. Pediatrics, 146(1), e20201306.

Collins, W. A., Laursen, B., Mortensen, N., Luebker, C., \& Ferreira, M. (1997). Conflict processes and transitions in parent and peer relationships: Implications for autonomy and regulation. Journal of Adolescent Research, 12(2), 178-198.

Cooper, C., \& Cooper, R. (1992). Links between adolescents' relationships with their parents and peers, models evidence and mechanisms. In R. D. Parke \& G. W. Ladd (Eds.), Family-Peer Relationships: Modes of Linkage. New Jersey: Lawrence Earikbaum.

Crouter, A. C., Head, M. R., McHale, S. M., \& Tucker, C. J. (2004). Family time and the psychosocial adjustment of adolescent siblings and their parents. Journal of Marriage and Family, 66(1), 147-162. 
Da Silva, L., Sanson, A., Smart, D., \& Toumbourou, J. (2004). Civic responsibility among Australian adolescents: Testing two competing models. Journal of Community Psychology, 32, 229-255.

Desilver, D. (2019). In the U.S., teen summer jobs aren't what they used to be. Pew Research Center. Retrieved from: https://pewrsr.ch/2ZPMy59.

De Goede, I. H., Branje, S. J., Delsing, M. J., \& Meeus, W. H. (2009). Linkages over time between adolescents' relationships with parents and friends. Journal of Youth and Adolescence, 38(10), 13041315.

del Valle, J. F., Bravo, A., \& Lopez, M. (2010). Parents and peers as providers of support in adolescents' social network: a developmental perspective. Journal of Community Psychology, 38(1), 16-27.

Denault, A., \& Poulin, F. (2009). Predictors of adolescent participation in organized activities: A fiveyear longitudinal study. Journal of Research on Adolescence, 19, 287-311.

Ellis, W. E., Dumas, T. M., \& Forbes, L. M. (2020). Physically isolated but socially connected: Psychological adjustment and stress among adolescents during the initial COVID-19 crisis. Canadian Journal of Behavioural Science/Revue canadienne des sciences du comportement, 52(3), 177.

Ferrar, K., Chang, C., Li, M., \& Olds, T. S. (2013). Adolescent time use clusters: a systematic review. Journal of Adolescent Health, 52(3), 259-270.

Finch, J.F., Barrera, M., Jr., Okun, M.A., Bryant, W.H.M., Pool, G. J., \& Snow-Turek, A. L. (1997). Factor structure of received social support: Dimensionality and the prediction of depression and life satisfaction. Journal of Social and Clinical Psychology, 16, 323-342.

Friedman, M. S., Marshal, M. P., Guadamuz, T. E., Wei, C., Wong, C. F., Saewyc, E. M., \& Stall, R. (2011). A meta-analysis of disparities in childhood sexual abuse, parental physical abuse, and peer victimization among sexual minority and sexual nonminority individuals. American Journal of Public Health, 101(8), 1481-1494.

Fuligni, A. J., Tseng, V., \& Lam, M. (1999). Attitudes toward family obligations among American adolescents with Asian, Latin American, and European backgrounds. Child Development, 70(4), 1030-1044.

Furman, W., \& Rose, A. J. (2015). Friendships, romantic relationships, and peer relationships. In R. M. Lerner (Ed.), Handbook of child psychology and developmental science (7th ed., pp. 1-43). Hoboken, NJ: John Wiley \& Sons.

Gaby, S. (2017). The civic engagement gap (s): Youth participation and inequality from 1976 to 2009. Youth \& Society, 49(7), 923-946.

Gager, C. T., Sanchez, L. A., \& Demaris, A. (2009). Whose time is it? The effect of employment and work/family stress on children's housework. Journal of Family Issues, 30(11), 1459-1485. 
Garton, A. F., Harvey, R., \& Price, C. (2004). Influence of perceived family environment on adolescent leisure participation. Australian Journal of Psychology, 56(1), 18-24.

Gil de Zúñiga, H., Jung, N., \& Valenzuela, S. (2012). Social media use for news and individuals' social capital, civic engagement and political participation. Journal of Computer-Mediated Communication, 17(3), 319-336.

Good, M., Willoughby, T., \& Fritjers, J. (2009). Just another club? The distinctiveness of the relation between religious service attendance and adolescent psychosocial adjustment. Journal of Youth and Adolescence, 38(9), 1153-1171.

Gracia, P., Garcia- Roman, J., Oinas, T., \& Anttila, T. (2020). Child and Adolescent Time Use: A Cross- National Study. Journal of Marriage and Family, 82(4), 1304-1325.

Hardway, C., \& Fuligni, A. J. (2006). Dimensions of family connectedness among adolescents with mexican, chinese, and european backgrounds. Developmental Psychology, 42(6), 1246-1258.

Hardy, S. A., Nelson, J. M., Moore, J. P., \& King, P. E. (2019). Processes of religious and spiritual influence in adolescence: A systematic review of 30 years of research. Journal of Research on Adolescence, 29(2), 254-275.

Harris, C., Straker, L., \& Pollock, C. (2017). A socioeconomic related 'digital divide' exists in how, not if, young people use computers. PloS one, 12(3), e0175011.

Hope, E. C., Cryer-Coupet, Q. R., \& Stokes, M. N. (2020). Race-related stress, racial identity, and activism among young Black men: A person-centered approach. Developmental Psychology, 56(8), 1484-1495.

Huebner, A. J., \& Mancini, J. A. (2003). Shaping structured out-of-school time use among youth: The effects of self, family, and friend systems. Journal of Youth and Adolescence, 32(6), 453-463.

Hunt, E., \& McKay, E. A. (2015). What can be learned from adolescent time diary research. Journal of Adolescent Health, 56(3), 259-266.

Hunt, M. G., Marx, R., Lipson, C., \& Young, J. (2018). No more FOMO: Limiting social media decreases loneliness and depression. Journal of Social and Clinical Psychology, 37(10), 751-768.

Iannotti, R. J., Kogan, M. D., Janssen, I., \& Boyce, W. F. (2009). Patterns of adolescent physical activity, screen-based media use, and positive and negative health indicators in the US and Canada. Journal of Adolescent Health, 44(5), 493-499.

Jenkins, H., Shresthova, S., Gamber-Thompson, L., Kligler-Vilenchik, N., \& Zimmerman, A. (2016). By any media necessary: The new youth activism. New York: NYU Press.

Keijsers, L., Frijns, T., Branje, S. J. T., \& Meeus, W. (2009). Developmental links of adolescent disclosure, parental solicitation, and control with delinquency: Moderation by parental support. Developmental Psychology, 45(5), 1314-1327. 
Kelly, Y., Zilanawala, A., Booker, C., \& Sacker, A. (2018). Social media use and adolescent mental health: Findings from the UK Millennium Cohort Study. EClinicalMedicine, 6, 59-68.

Klineberg, E., Clark, C., Bhui, K. S., Haines, M. M., Viner, R. M., Head, J., ... \& Stansfeld, S. A. (2006). Social support, ethnicity and mental health in adolescents. Social Psychiatry and Psychiatric Epidemiology, 41(9), 755-760.

Kuhfeld, Megan, James Soland, Beth Tarasawa, Angela Johnson, Erik Ruzek, and Jing Liu. (2020). Projecting the potential impacts of COVID-19 school closures on academic achievement. EdWorkingPaper, 20-226.

Larson, R. W., \& Verma, S. (1999). How children and adolescents spend time across the world: work, play, and developmental opportunities. Psychological Bulletin, 125(6), 701-736.

Lee, S. J., Bartolic, S., \& Vandewater, E. A. (2009). Predicting children's media use in the USA: Differences in cross- sectional and longitudinal analysis. British Journal of Developmental Psychology, 27(1), 123-143.

Lenhart, A., Duggan, M., Perrin, A., Stepler, R., Rainie, L., \& Parker, K. (2015). Teens, social media \& technology overview 2015. Washington DC: Pew Research Center. http://www.pewinternet.org/2015/04/09/teens-social-mediatechnology-2015/

Lerner, R. M., Wang, J., Champine, R. B., Warren, D. J., \& Erickson, K. (2014). Development of civic engagement: Theoretical and methodological issues. International Journal of Developmental Science, 8(3-4), 69-79.

Lin, L. Y., Sidani, J. E., Shensa, A., Radovic, A., Miller, E., Colditz, J. B., ... \& Primack, B. A. (2016). Association between social media use and depression among US young adults. Depression and Anxiety, 33(4), 323-331.

Linver, M. R., Roth, J. L., \& Brooks-Gunn, J. (2009). Patterns of adolescents' participation in organized activities: Are sports best when combined with other activities?. Developmental Psychology, 45(2), 354-367.

Little, T. D., \& Rhemtulla, M. (2013). Planned missing data designs for developmental researchers. Child Development Perspectives, 7(4), 199-204.

Malczyk, B. R., \& Lawson, H. A. (2017). Parental monitoring, the parent-child relationship and children's academic engagement in mother-headed single-parent families. Children and Youth Services Review, 73, 274-282.

Masten, A. S., \& Narayan, A. J. (2012). Child development in the context of disaster, war, and terrorism: Pathways of risk and resilience. Annual Review of Psychology, 63, 227-257. 
Metzger, A., Crean, H. F., \& Forbes-Jones, E. L. (2009). Patterns of organized activity participation in urban, early adolescents: Associations with academic achievement, problem behaviors, and perceived adult support. The Journal of Early Adolescence, 29(3), 426-442.

Micheli, M. (2016). Social networking sites and low-income teenagers: between opportunity and inequality. Information, Communication \& Society, 19(5), 565-581.

Mortimer, J. T. (2010). The benefits and risks of adolescent employment. The Prevention Researcher, $17(2), 8-11$.

Nickerson, A. B., \& Nagle, R. J. (2005). Parent and peer attachment in late childhood and early adolescence. The Journal of Early Adolescence, 25(2), 223-249.

NPR. (2020). The Impact of Coronavirus on Households Across America. NPR, Robert Wood Johnson Foundation, \& Harvard T. H. Chan School of Public Health. https://media.npr.org/assets/img/2020/09/08/cities-report-090920-final.pdf

Orben, A., Tomova, L., \& Blakemore, S.-J. (2020). The effects of social deprivation on adolescent development and mental health. The Lancet Child \& Adolescent Health, 4(8), 634-640.

Parker, K. E., Salmon, J., Villanueva, K., Mavoa, S., Veitch, J., Brown, H. L., \& Timperio, A. (2019). Ecological correlates of activity-related behavior typologies among adolescents. BMC Public Health, 19(1), 1041.

Poteat, V. P., Calzo, J. P., \& Yoshikawa, H. (2018). Gay-Straight Alliance involvement and youths' participation in civic engagement, advocacy, and awareness-raising. Journal of Applied Developmental Psychology, 56, 13-20.

Rickman, A. (2018). Adolescence, Girlhood, and Media Migration: US Teens' Use of Social Media to Negotiate Offline Struggles. Lexington Books.

Rideout, V. J., \& Robb, M. B. (2019). The common sense census: Media use by tweens and teens. San Francisco, CA: Common Sense Media.

Roach, A. (2018). Supportive peer relationships and mental health in adolescence: An integrative review. Issues in Mental Health Nursing, 39(9), 723-737.

Robnett, R. D., \& Leaper, C. (2013). Friendship groups, personal motivation, and gender in relation to high school students' STEM career interest. Journal of Research on Adolescence, 23, 652-664.

Russell, S. T., \& Fish, J. N. (2016). Mental health in lesbian, gay, bisexual, and transgender (LGBT) youth. Annual Review of Clinical Psychology, 12, 465-487.

Schwan, K. J., Fallon, B., \& Milne, B. (2018). "The one thing that actually helps": Art creation as a selfcare and health-promoting practice amongst youth experiencing homelessness. Children and Youth Services Review, 93, 355-364. 
Sela, Y., Zach, M., Amichay-Hamburger, Y., Mishali, M., \& Omer, H. (2020). Family environment and problematic internet use among adolescents: the mediating roles of depression and fear of missing out. Computers in Human Behavior, 106, 106226.

Shanahan, M. J., \& Flaherty, B. P. (2001). Dynamic patterns of time use in adolescence. Child Development, 72(2), 385-401.

Sharp, E. H., Tucker, C. J., Baril, M. E., Van Gundy, K. T., \& Rebellon, C. J. (2015). Breadth of participation in organized and unstructured leisure activities over time and rural adolescents' functioning. Journal of Youth and Adolescence, 44(1), 62-76.

Shresthova, S. (2013). Between storytelling and surveillance: American muslim youth negotiate culture, politics and participation. Los Angeles, CA: Digital Media and Learning Research Hub.

Silke, C., Brady, B., Boylan, C., \& Dolan, P. (2018). Factors influencing the development of empathy and pro-social behaviour among adolescents: A systematic review. Children and Youth Services Review, 94, 421-436.

Smith, C., Denton, M. L., Faris, R., \& Regnerus, M. (2002). Mapping American adolescent religious participation. Journal for the Scientific Study of Religion, 41(4), 597-612.

Stiglic, N., \& Viner, R. M. (2019). Effects of screentime on the health and well-being of children and adolescents: a systematic review of reviews. BMJ Open, 9(1), e023191.

Tilton-Weaver, L. C., \& Galambos, N. L. (2003). Adolescents' characteristics and parents' beliefs as predictors of parents' peer management behaviors. Journal of Research on Adolescence, 13, 269 300.

Trainor, S., Delfabbro, P., Anderson, S., \& Winefield, A. (2010). Leisure activities and adolescent psychological well-being. Journal of Adolescence, 33(1), 173-186.

Twenge, J. M., Joiner, T. E., Rogers, M. L., \& Martin, G. N. (2018). Increases in depressive symptoms, suicide-related outcomes, and suicide rates among US adolescents after 2010 and links to increased new media screen time. Clinical Psychological Science, 6(1), 3-17.

Updegraff, K. A., McHale, S. M., Whiteman, S. D., Thayer, S. M., \& Crouter, A. C. (2006). The nature and correlates of Mexican- American adolescents' time with parents and peers. Child Development, 77(5), 1470-1486.

U.S. Bureau of Labor Statistics. (2020). Employment Situation Summary. Retrieved from: https://www.bls.gov/news.release/empsit.nr0.htm

Valkenburg, P. M., \& Peter, J. (2007). Preadolescents' and adolescents' online communication and their closeness to friends. Developmental Psychology, 43(2), 267.

van Dorn, A., Cooney, R. E., \& Sabin, M. L. (2020). COVID-19 exacerbating inequalities in the US. Lancet, 395, 1243-1244 
Vossen, H. G., \& Valkenburg, P. M. (2016). Do social media foster or curtail adolescents' empathy? A longitudinal study. Computers in Human Behavior, 63,118-124.

Way, N. (2011). Deep secrets: Boys'friendships and the crisis of connection. Cambridge, MA US: Harvard University Press.

Wilkinson, R. B. (2004). The role of parental and peer attachment in the psychological health and selfesteem of adolescents. Journal of Youth and Adolescence, 33(6), 479-493.

Wolf, S., Aber, J. L., \& Morris, P. A. (2015). Patterns of time use among low-income urban minority adolescents and associations with academic outcomes and problem behaviors. Journal of Youth and Adolescence, 44(6), 1208-1225.

Wray-Lake, L., Arruda, E. H., \& Schulenberg, J. E. (2020). Civic development across the transition to adulthood in a national U.S. sample: Variations by race/ethnicity, parent education, and gender. Developmental Psychology, 56(10), 1948-1967.

Wray-Lake, L., Shubert, J., Lin, L., \& Starr, L.R. (2019). Examining associations between civic engagement and depressive symptoms from adolescence to young adulthood in a national U.S. Sample. Applied Developmental Science, 23(2), 119-131.

Wu, C. S. T., Wong, H. T., Yu, K. F., Fok, K. W., Yeung, S. M., Lam, C. H., \& Liu, K. M. (2016). Parenting approaches, family functionality, and internet addiction among Hong Kong adolescents. BMC Pediatrics, 16(1), 1-10.

Ybarra, M. L., Mitchell, K. J., Palmer, N. A., \& Reisner, S. L. (2015). Online social support as a buffer against online and offline peer and sexual victimization among US LGBT and non-LGBT youth. Child Abuse \& Neglect, 39, 123-136.

Yuen, C. X., Fuligni, A. J., Gonzales, N., \& Telzer, E. H. (2018). Family first? The costs and benefits of family centrality for adolescents with high-conflict families. Journal of Youth and Adolescence, $47(2), 245-259$. 
Table 1. Descriptive statistics and bivariate correlations of study variables.

\begin{tabular}{|c|c|c|c|c|c|}
\hline & $\mathrm{M}(\mathrm{SD})$ & $\begin{array}{l}\text { Parent } \\
\text { support }\end{array}$ & $\begin{array}{l}\text { Parent } \\
\text { conflict }\end{array}$ & $\begin{array}{l}\text { Friend } \\
\text { support }\end{array}$ & $\begin{array}{l}\text { In-Person Time } \\
\text { with Friends }\end{array}$ \\
\hline \multicolumn{6}{|l|}{ Family and Peer Relationships } \\
\hline Parent support & - & - & & & \\
\hline Parent conflict & - & $-0.28 * * *$ & - & & \\
\hline Friend support & - & $0.26 * * *$ & 0.06 & - & \\
\hline In-person time with friends & $2.34(1.13)$ & $0.14 *$ & -0.02 & $0.30 * * *$ & - \\
\hline \multicolumn{6}{|l|}{ Demographic Factors } \\
\hline Female $^{\mathrm{a}}$ & $0.51(0.50)$ & $0.05^{*}$ & 0.03 & 0.01 & -0.00 \\
\hline Non-binary ${ }^{\mathrm{a}}$ & $0.08(0.27)$ & $-0.05 * * *$ & $0.04 * *$ & 0.01 & -0.00 \\
\hline Latin $x^{b}$ & $0.20(0.40)$ & -0.02 & -0.00 & -0.01 & $-0.06 * *$ \\
\hline Asian ${ }^{\mathrm{b}}$ & $0.17(0.38)$ & -0.03 & 0.00 & 0.01 & -0.03 \\
\hline Other race/ethnicity ${ }^{\mathrm{b}}$ & $0.13(0.33)$ & 0.02 & 0.01 & 0.01 & -0.02 \\
\hline Parents' education & $2.39(0.71)$ & 0.06 & -0.03 & -0.02 & $0.12 * * *$ \\
\hline LGBQ & $0.53(0.50)$ & $-0.07 * *$ & $0.07 * *$ & 0.01 & -0.03 \\
\hline \multicolumn{6}{|l|}{ Time Use } \\
\hline Educational activities & $1.40(1.82)$ & $0.20^{*}$ & -0.08 & 0.13 & -0.03 \\
\hline Playing video games & $1.51(1.70)$ & $-0.17 *$ & 0.03 & -0.06 & $-0.27 * *$ \\
\hline Watching shows or movies & $2.23(1.59)$ & $-0.16^{*}$ & $0.27 * * *$ & 0.06 & -0.14 \\
\hline Watching or reading the news & $0.56(0.87)$ & 0.03 & 0.07 & 0.01 & -0.05 \\
\hline Time with family & $2.05(1.82)$ & $0.63 * * *$ & $-0.24 * *$ & -0.02 & 0.09 \\
\hline Virtual interactions with friends & $2.22(1.75)$ & $-0.26 * *$ & $0.22 * *$ & $0.60 * * *$ & 0.03 \\
\hline Social media time & $2.41(1.67)$ & $-0.28 * * *$ & $0.23 * *$ & $0.28 * * *$ & -0.14 \\
\hline Working out or exercising & $0.59(0.84)$ & $0.11 * *$ & $-0.09 *$ & 0.01 & 0.06 \\
\hline Working for pay & $1.05(1.93)$ & 0.03 & -0.11 & 0.07 & $0.40 * * *$ \\
\hline Doing chores and family work & $0.86(1.08)$ & 0.01 & $0.13 *$ & 0.08 & $-0.14 * *$ \\
\hline Religious, spiritual, or meditation & $0.18(0.48)$ & $0.09 * * *$ & $-0.06 * *$ & 0.04 & $0.08 * *$ \\
\hline Helping others & $0.41(0.87)$ & $0.10^{*}$ & $0.12 * *$ & $0.12 * *$ & $0.11 * *$ \\
\hline Engaging in online political action & $0.36(0.79)$ & $-0.09 *$ & $0.19^{* * *}$ & 0.05 & -0.04 \\
\hline Creating art or music & $0.71(1.15)$ & $-0.12 *$ & $0.13 *$ & 0.10 & -0.06 \\
\hline
\end{tabular}

Notes: $\mathrm{M}=$ mean, $\mathrm{SD}=$ standard deviation. ${ }^{\mathrm{a}}$ Reference group $=$ male. ${ }^{\mathrm{b}}$ Reference group $=$ white.

$* p<0.05, * * p<0.01, * * * p<0.001$. 
Table 2. Fit indices for latent profile analysis on adolescent time use variables

\begin{tabular}{lllllll}
\hline $\begin{array}{l}\text { Number } \\
\text { of classes }\end{array}$ & Fit statistics & & & & & \\
\cline { 2 - 7 } & AIC & BIC & ABIC & $\begin{array}{l}\text { LMR-LRT } \\
(\mathrm{p} \text {-value })\end{array}$ & $\begin{array}{l}\text { BLRT } \\
(\mathrm{p} \text {-value })\end{array}$ & Entropy \\
\hline 1 & 25080.091 & 25200.971 & 25112.087 & - & - & - \\
2 & 23931.164 & 24116.802 & 23980.301 & $\begin{array}{l}1166.615 \\
(<0.001)\end{array}$ & $\begin{array}{l}1178.927 \\
(<0.001)\end{array}$ & 1.00 \\
& & & & $\begin{array}{l}317.806 \\
321.16\end{array}$ & 0.89 \\
3 & 23640.004 & 23890.400 & 23706.282 & $\begin{array}{l}31<0.001) \\
(<0.001)\end{array}$ & \\
4 & 23055.275 & 23370.428 & 23138.693 & $\begin{array}{l}417.38 \\
(0.0168)\end{array}$ & $\begin{array}{l}421.785 \\
(<0.001)\end{array}$ & 0.99 \\
\hline
\end{tabular}

Notes: AIC: Akaike's Information Criterion; BIC: Bayesian Information Criterion; ABIC: Sample sizeadjusted BIC; LMR-LRT: Lo-Mendell-Rubin likelihood ratio test; BLRT: Bootstrap likelihood ratio test 
Table 3. Multinomial logistic regression model predicting class membership.

\begin{tabular}{|c|c|c|c|c|c|c|c|c|c|}
\hline & \multicolumn{6}{|c|}{ Model 1} & \multirow{2}{*}{\multicolumn{3}{|c|}{$\begin{array}{c}\text { Model } 2 \\
\text { Media Users vs. } \\
\text { Education-Focused }\end{array}$}} \\
\hline & \multicolumn{3}{|c|}{$\begin{array}{l}\text { Education-Focused vs. } \\
\text { Workers }\end{array}$} & \multicolumn{3}{|c|}{$\begin{array}{l}\text { Media Users vs. } \\
\text { Workers }\end{array}$} & & & \\
\hline & $\mathrm{B}$ & SE & $\begin{array}{c}\text { OR } \\
(95 \% \mathrm{CI})\end{array}$ & B & SE & $\begin{array}{c}\text { OR } \\
(95 \% \mathrm{CI})\end{array}$ & B & SE & $\begin{array}{c}\text { OR } \\
(95 \% \mathrm{CI})\end{array}$ \\
\hline \multicolumn{10}{|l|}{ Demographics } \\
\hline Female & -0.53 & 0.24 & $\begin{array}{l}0.59 * * \\
(0.39-0.87)\end{array}$ & 0.12 & 0.27 & $\begin{array}{l}1.13 \\
(0.72-1.77)\end{array}$ & 0.66 & 0.24 & $\begin{array}{l}1.93 * \\
(1.30-2.86)\end{array}$ \\
\hline Non-binary & 1.05 & 0.62 & $\begin{array}{l}2.87 \\
(1.03-8.01)\end{array}$ & 1.31 & 0.63 & $\begin{array}{l}3.71 \\
(1.31-10.52)\end{array}$ & 0.26 & 0.39 & $\begin{array}{l}1.29 \\
(0.68-2.46)\end{array}$ \\
\hline Latinx & 0.65 & 0.35 & $\begin{array}{l}1.91 \\
(1.08-3.37)\end{array}$ & 0.89 & 0.37 & $\begin{array}{l}2.42 \\
(1.32-4.46)\end{array}$ & 0.24 & 0.30 & $\begin{array}{l}1.27 \\
(0.78-2.07)\end{array}$ \\
\hline Asian & 1.05 & 0.36 & $\begin{array}{l}2.87 \\
(1.59-5.16)\end{array}$ & 0.81 & 0.40 & $\begin{array}{l}2.25 \\
(1.17-4.33)\end{array}$ & -0.24 & 0.32 & $\begin{array}{l}0.79 \\
(0.46-1.34)\end{array}$ \\
\hline Other race/ethnicity & 0.79 & 0.39 & $\begin{array}{l}2.20 \\
(1.15-4.183)\end{array}$ & 0.68 & 0.43 & $\begin{array}{l}1.98 \\
(0.98-3.98)\end{array}$ & -0.10 & 0.34 & $\begin{array}{l}0.90 \\
(0.51-1.58)\end{array}$ \\
\hline Parents' education & 0.27 & 0.18 & $\begin{array}{l}1.31 \\
(0.98-1.76)\end{array}$ & 0.12 & 0.19 & $\begin{array}{l}1.13 \\
(0.83-1.54)\end{array}$ & -0.15 & 0.17 & $\begin{array}{l}0.86 \\
(0.65-1.13)\end{array}$ \\
\hline LGBQ & -0.20 & 0.24 & $\begin{array}{l}0.82 \\
(0.55-1.22)\end{array}$ & 0.51 & 0.27 & $\begin{array}{l}1.66 \\
(1.07-2.57)\end{array}$ & 0.70 & 0.23 & $\begin{array}{l}2.02 * \\
(1.37-2.96)\end{array}$ \\
\hline \multicolumn{10}{|l|}{ Relationships } \\
\hline Parent support & 0.40 & 0.16 & $\begin{array}{l}1.49 * \\
(1.15-1.92)\end{array}$ & -0.16 & 0.18 & $\begin{array}{l}0.85 \\
(0.64-1.14)\end{array}$ & -0.56 & 0.16 & $\begin{array}{l}0.57 * * * \\
(0.44-0.74)\end{array}$ \\
\hline Parent conflict & 0.14 & 0.15 & $\begin{array}{l}1.15 \\
(0.90-1.48)\end{array}$ & 0.25 & 0.15 & $\begin{array}{l}1.29 \\
(1.00-1.65)\end{array}$ & 0.11 & 0.13 & $\begin{array}{l}1.12 \\
(0.91-1.37)\end{array}$ \\
\hline Friend support & -0.31 & 0.16 & $\begin{array}{l}0.73 * \\
(0.57-0.95)\end{array}$ & 0.30 & 0.17 & $\begin{array}{l}1.35 \\
(1.02-1.78)\end{array}$ & 0.61 & 0.15 & $\begin{array}{l}1.84 * * \\
(1.45-2.34)\end{array}$ \\
\hline $\begin{array}{l}\text { In-person time w/ } \\
\text { friends }\end{array}$ & -0.27 & 0.11 & $\begin{array}{l}0.76 * * \\
(0.64-0.91)\end{array}$ & -0.44 & 0.12 & $\begin{array}{l}0.65 * * * \\
(0.53-0.79)\end{array}$ & -0.17 & 0.11 & $\begin{array}{l}0.85 \\
(0.71-1.01)\end{array}$ \\
\hline
\end{tabular}

Notes: OR $=$ Odds ratios, where values higher than 1 refer to higher odds and values less than 1 refer to lower odds.

In Model 1, the Workers class was specified as the reference group.

In Model 2, the Education-Focused class was specified as the reference group.

${ }^{\text {a Reference }}=$ male. ${ }^{\text {b }}$ Reference $=$ white.

$* p<0.05, * * p<0.01, * * * p<0.001$. 
Adolescent Time Use and Relationships 41

Figure 1. Profiles of adolescent time use.

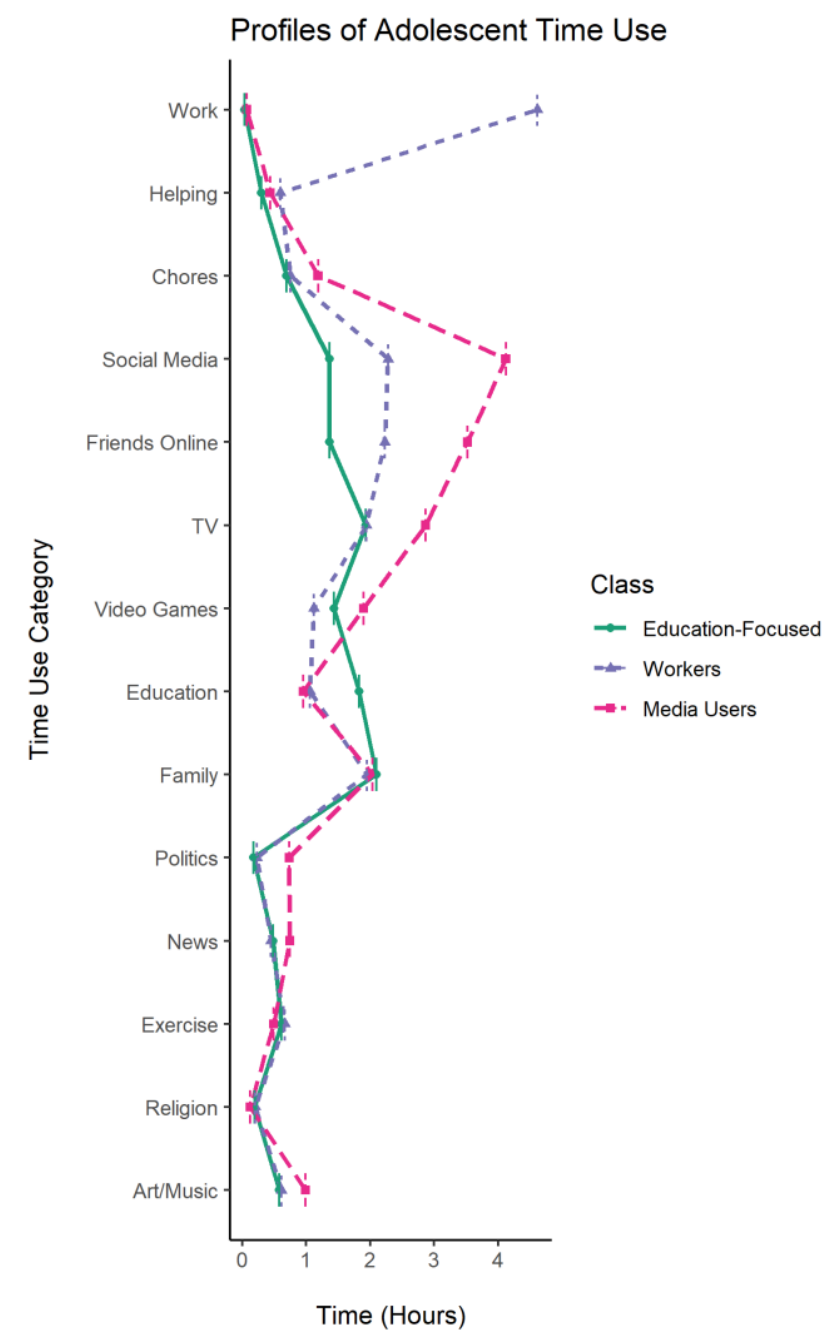

Note. Point estimates represent means on a given time use category for each class. 

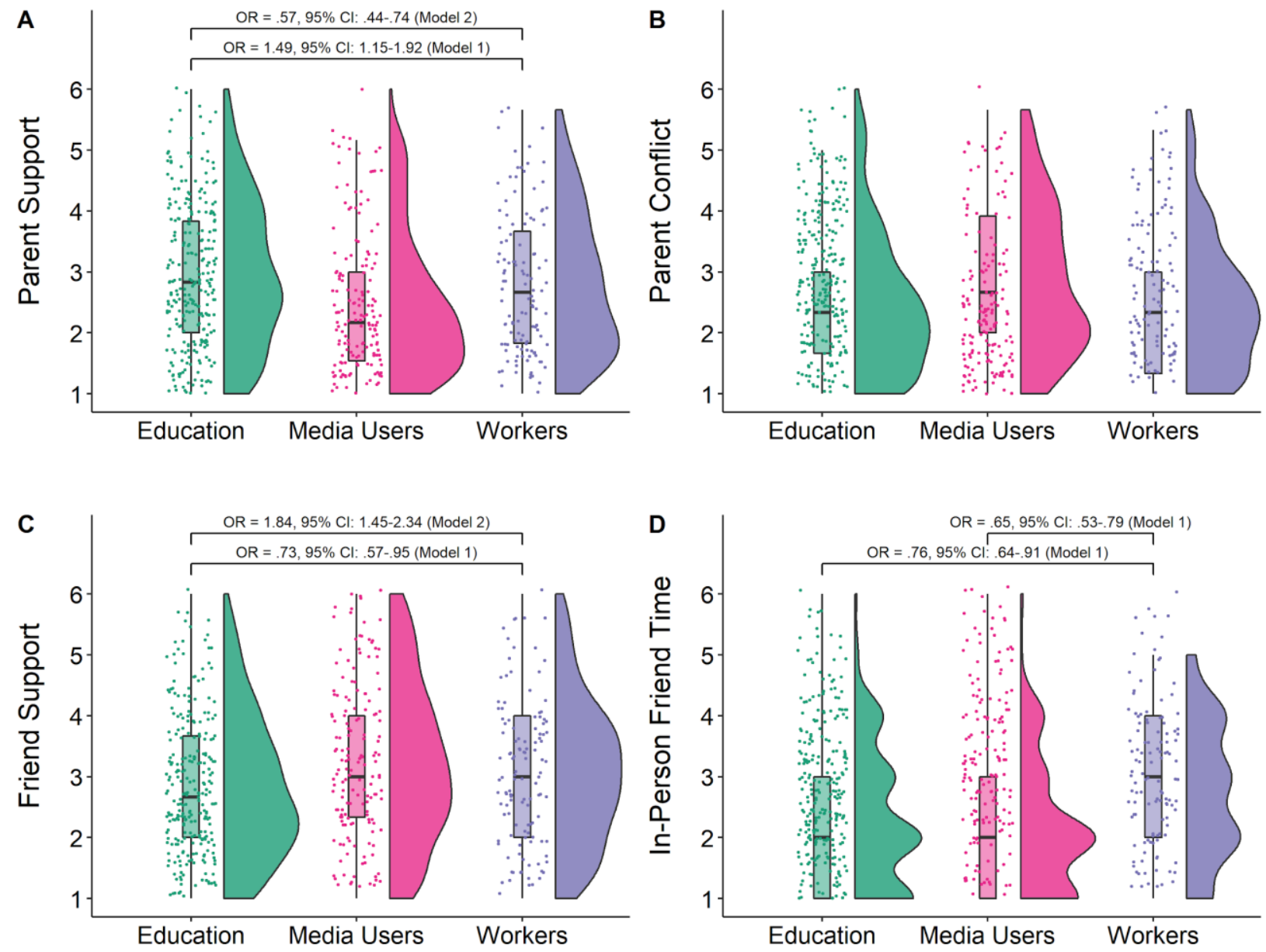

Figure 2. Figure 2a: Differences in parent support by adolescent time use class. Figure 2b: Differences in parent conflict by adolescent time use class. Figure 2c: Differences in friend support by adolescent time use class. Figure 2d: Differences in in-person friend time by adolescent time use class. 